\title{
Spatial and temporal characteristics of water resources in Argun River basin based on multi-source data
}

\author{
LIU HUI, BAIYIN BAOLIGAO, CHEN XINGRU \& WANG XIUYING \\ China Institute of Water Resources and Hydropower Research, A1 Fuxing Road D505, Beijing, 100080, China \\ wuyouliuhui@163.com
}

\begin{abstract}
The wetlands of Argun River basin are important habitat for birds migrating between East Asia and Australia. Investigating spatial and temporal characteristics and evolution trends of water resources of this region is of significant importance for sustainable water management and coping with climate change. Using in-field data and NCEP (National Centers for Environmental Prediction) reanalysis data, the MannKendall method and wavelet analysis method are applied to obtain the temporal characteristics. Spatial distribution analysis includes use of gridded data and data along the river. The results illustrate that water resources of upstream regions show descending trends, and the temporal distribution of the flow presents an "M" shape. Precipitation of this region has 10-year and 24-year scale primary periods. The period analysis is verified by the large flood in 2013, and forecasts that the next high flow year could be around 2021.
\end{abstract}

Key words Argun River; characteristics of water resources; Mann-Kendall; wavelet analysis

\section{INTRODUCTION}

The Argun River in in northeast China and is a trans-boundary river of China and Russia, flowing from west to northeast. Wetlands along the Argun River are called the Daurian wetland, which is an important habitat for birds migrating between East Asia and Australia. Grassland in this region is of great significance for livestock and the natural carbon cycle. Investigation of the evolutionary trends of water resources and their spatial and temporal characteristics are of critical importance to the protection of Daurian wetland and ecosystem safety (Zhao, 2007; Zhang et al. 2011).

The Argun River basin consists of Hailar River system, Hulun Lake system and the main stream of the Argun River. Water levels of Hulun Lake declined in recent years, and the wetland area of Hulun Lake is shrinking; its hydraulic connection with the Argun River was disconnected in recent years. More than $90 \%$ of water of the upper Argun River is from the Hailar River. Thus, in this research we focus on the water resources of the Hailar River basin and the main stream of Argun River basin (the dashed line is the boundary of the research area in Fig. 1(a)).

Altitude of this area ranges from 368 to $1663 \mathrm{~m}$, with an average of $781 \mathrm{~m}$. Forest, grassland and cropland are the main vegetation types (Fig. 1(b)), which are classified based on the MCD12Q1 data with a resolution of $500 \mathrm{~m}$. Rivers in this area are frozen from November to April, with a flow period from May to October, which starts earlier in the southern area.

\section{DATA}

Reliable data are one of the most critical factors for this research. Both in-field data and re-analysis data are applied to investigate the evolutionary trends of the hydrological factors, which determine the trend of water resources. In-field data are also used for obtaining the periodic characteristics of the precipitation and the temporal and spatial distribution of river flows.

Daily NCEP (National Centers for Environmental Prediction) CFSR (Climate Forecast System Reanalysis) data for 32 years, 1979-2010, are used to obtain the evolution trend of water resources; the spatial resolution is $30 \mathrm{~km}$ (http://globalweather.tamu.edu), and the research area consisted of 214 grids. With awareness of the little inter-annual variation of radiation and wind speed in a specific area, we supposed that the highest daily temperature and precipitation are the most important factors that determine the available water resources.

Observed data of hydrological stations in the main stream and large tributaries are used to analyse the spatial and temporal distribution of the water resources (Fig. 2(a)). All stations have flow records except the one on the main stream, as observed flow is rare on the main stream of Argun River, so the water level data of Shiwei station is used instead (Table 1). 

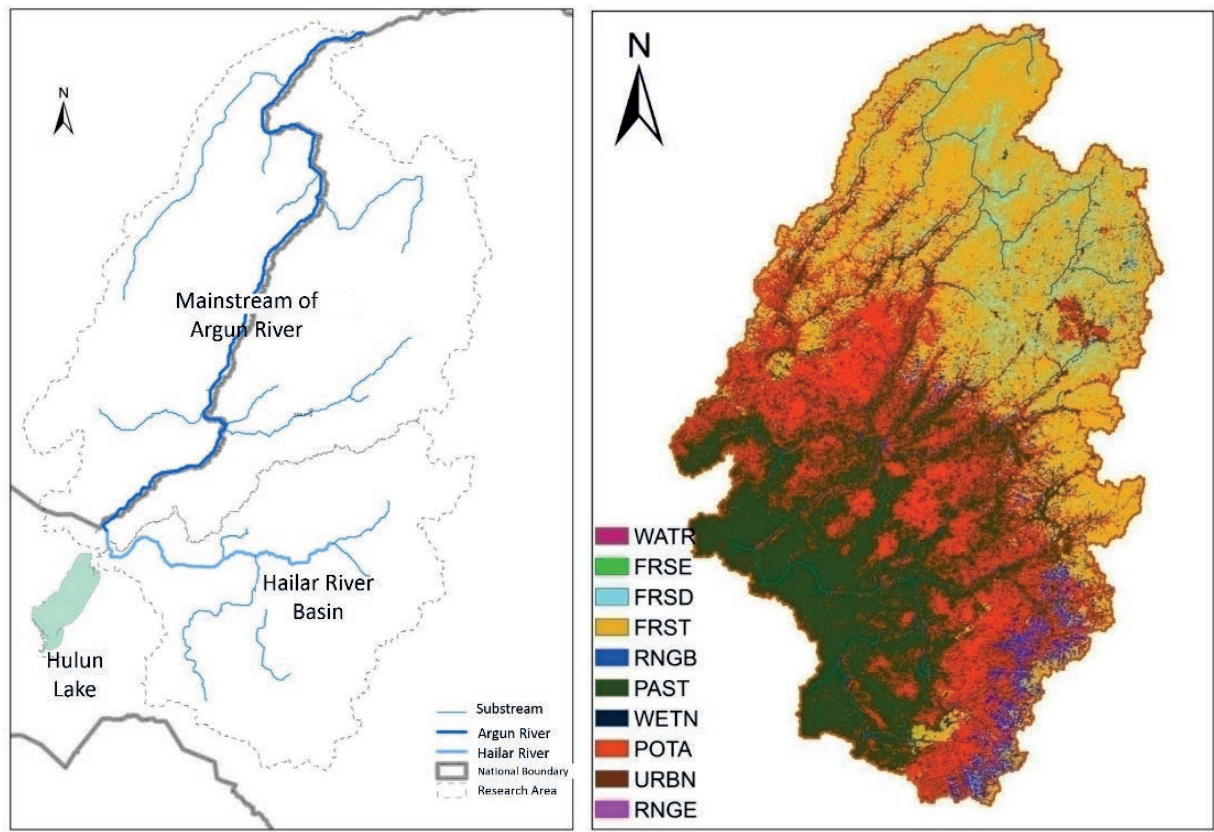

Fig. 1 (a) Research area and (b) vegetation types.
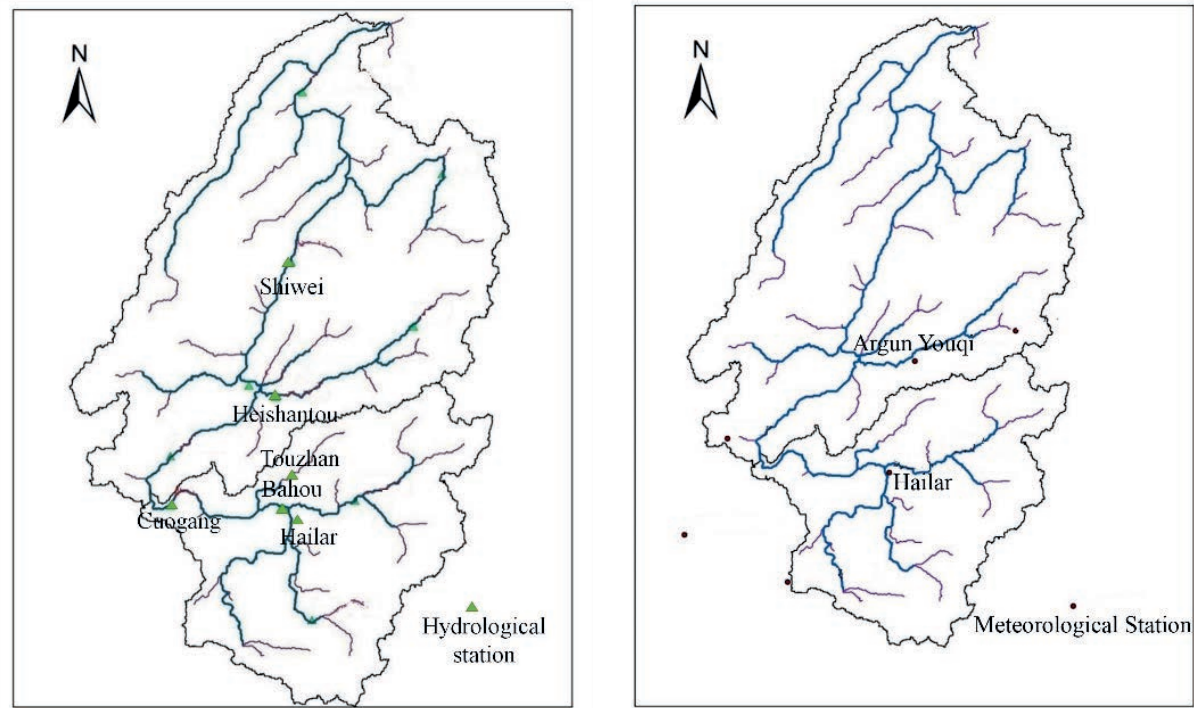

Fig. 2 (a) Hydrological stations and (b) meteorological stations.

Table 1 Hydrological data.

\begin{tabular}{llllll}
\hline Station name & LAT & LONG & Start Year & End Year & Data type \\
\hline Bahou & 49.27 & 119.73 & 1964 & 2012 & Flow \\
Hailar & 49.28 & 119.75 & 1960 & 1989 & Flow \\
Touzhan & 49.5 & 119.67 & 1960 & 1989 & Flow \\
Cuogang & 49.28 & 118.12 & 1960 & 1987 & Flow \\
Heishantou & 50.22 & 119.52 & 1960 & 2012 & Flow \\
Shiwei & 51.35 & 119.89 & 1940 & 1989 & Water level data \\
\hline
\end{tabular}

Daily precipitation data of 54 years at two meteorological stations located in the region of interest were used to investigate the periodic characteristics of water resources in the Argun River basin. The time spans is from 1957 to 2010 . The location of the two stations is illustrated in Fig. 2(b). 


\section{MANN-KENDALL METHOD}

The Mann-Kendall (M-K) test method is widely applied with non-normally distributed hydrological and meteorological data (Mann et al., 1998; Liu et al., 2012), as recommended by WMO (World Meteorological Organization). The variables $\tau, \sigma_{\tau}^{2}$ and $M$ are defined as follows:

$$
\begin{aligned}
& M=\tau / \sigma_{\tau} \\
& \tau=(4 s-1) /[N(N-1)]-1 \\
& \sigma_{\tau}^{2}=[2(2 N+5)] /[9 N(N-1)]
\end{aligned}
$$

where, $s$ is the number of times of $x_{i}<x_{j}$ happens in the data series $\left(x_{i}, x_{j}, \ldots, x_{N}\right) ; N$ is the total number of data; significance level $\alpha=5 \%$ if the data has a significant trend, $|M|>M_{\alpha / 2}=1.96$, positive $M$ means the data series has an ascending trend, negative $M$ means descending trend.

\section{WAVELET ANALYSIS METHOD}

Wavelet analysis is an effective method for detecting periodic signals in non-stationary time series, the signals of which can vary in both amplitude and frequency over long periods of time (Liu, 2005). In this paper, we used a typical wavelet (the Morlet) to decompose precipitation time series into time-frequency phase space. Here is a brief introduction of wavelet transform algorithms.

Suppose $\Psi(t) \in L^{1}(R) \cap L^{2}(R)$, and $\Psi(0)=0, C_{\Psi}=\int_{R}|\widehat{\Psi}(\omega)|^{2} /|\omega|<\infty$, where $R$ is real number, then $\Psi(t)$ is called the mother wavelet. If $\mathrm{f}(t)$ is square integrable, then its wavelet transform is the inner product of $\mathrm{f}(t)$ and $\Psi(t)$ :

$$
W_{f}(a, b)=f(t), \Psi_{a, b}(t)=\int_{-\infty}^{\infty} f(t) \bar{\Psi}_{a, b}(t) d t=\int_{-\infty}^{\infty} f(t) \frac{1}{\sqrt{a}} \bar{\Psi}\left(\frac{t-b}{a}\right) d t
$$

where, $\mathrm{f}(t) \epsilon L^{2}(R), a>0$.

The Morlet wavelet is defined as:

$$
\Psi(x)=\exp \left(-x^{2} / 2\right) \cos (5 x)
$$

The wavelet power spectrum is

$$
P_{f}(a)=\int\left|W_{f}(a, b)\right|^{2} d b
$$

\section{EVOLUTION TREND OF WATER RESOURCES}

The daily highest temperature and precipitation data from 1979 to 2010 are used for M-K analysis. The data are averaged over the flow period (May to October). The daily highest temperature of all grids have a significant trend; the trend of precipitation over the flow period in 84 grids is significant; yearly precipitation of 46 grids is significant.

A linear fitting method is applied to every grid with significant trend, and its change rate is calculated. The results are shown in Fig. 3.

Most of the upper stream areas are facing descending precipitation and higher temperature. Over the flow period, the southern part has a larger change rate of temperature than the north, the largest rate is about $0.9^{\circ} \mathrm{C} / 10$-years. And the upper stream areas have significant descending precipitation, the largest rate of which is about $-80 \mathrm{~mm} / 10$-years. Research by Gu (2011) based on in-field meteorological data reached a similar conclusion by the linear regression method. With higher temperature and less precipitation, the Hailar River basin and upper Argun River area would have less water resources.

\section{PERIODIC CHARACTERISTICS OF PRECIPITATION}

The meteorological stations of Hailar and Argun youqi were chosen as representative stations in the study area (Fig. 2(b)), for they are located near the middle of the region and on the two large tributaries (only results of the Argun youqi station are discussed below). 

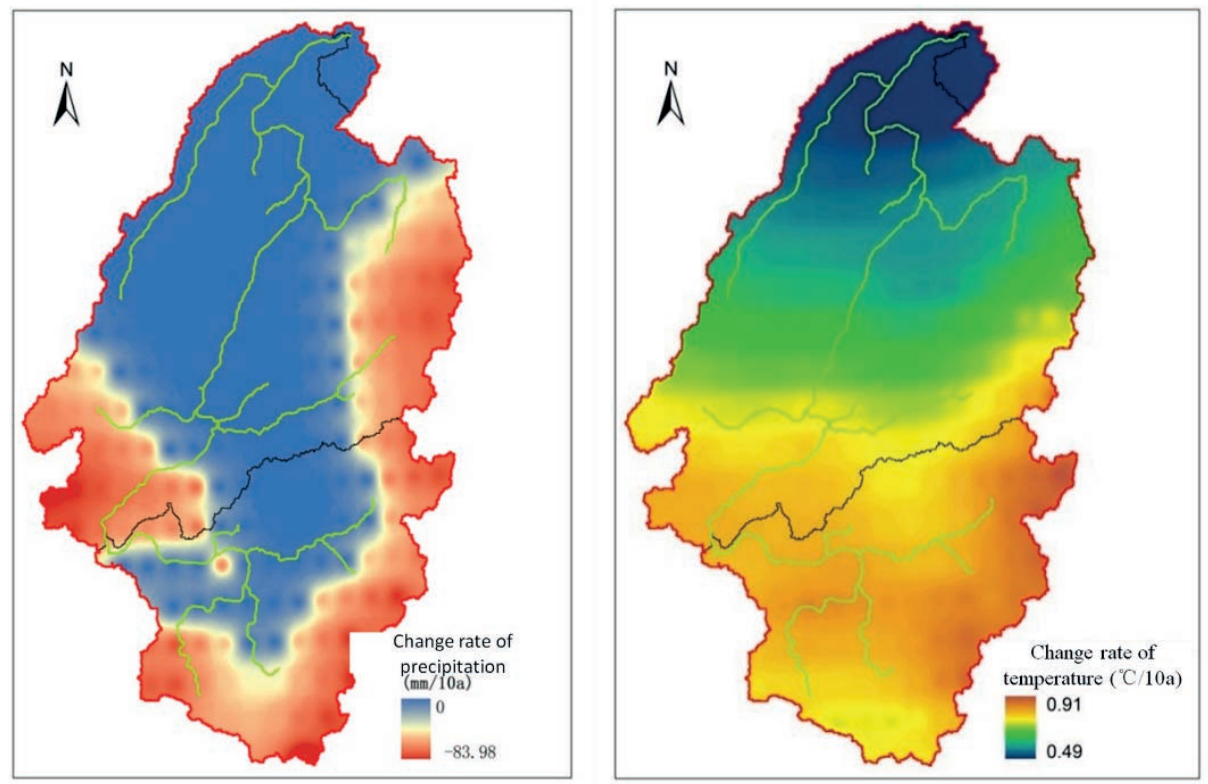

Fig. 3 (a) Change rate of precipitation, and (b) change rate of temperature.

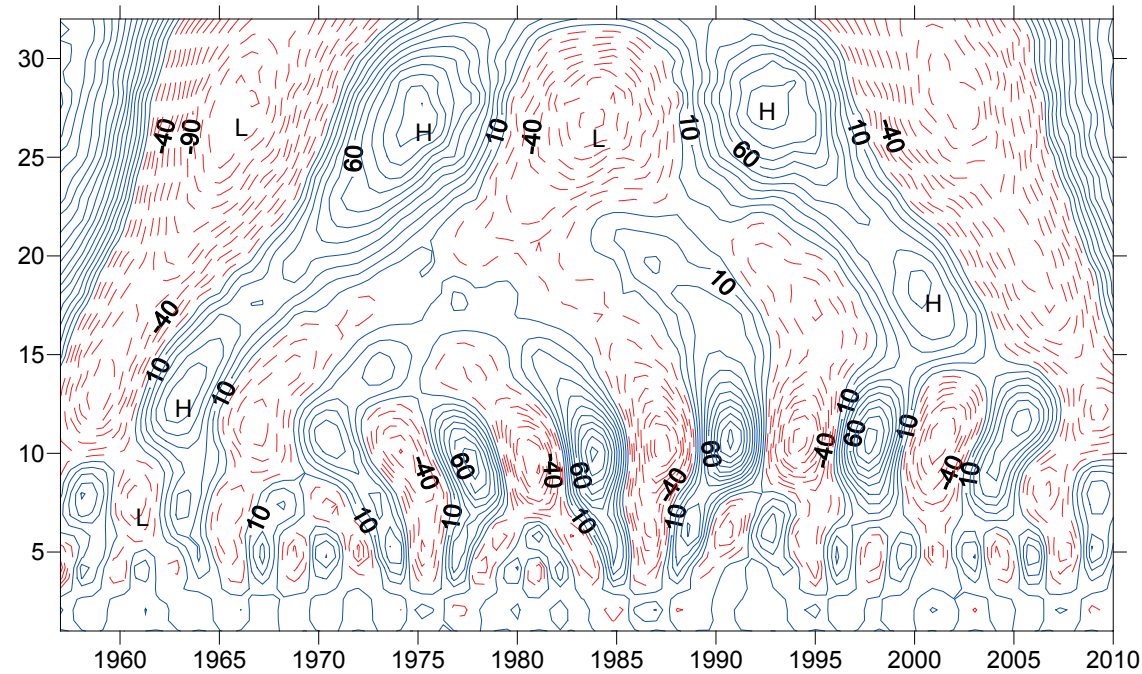

Fig. 4 Contour lines of the wavelet coefficient of real component at Argun Youqi station.

Contour lines of the wavelet coefficient of the real component illustrate the periodic change of various time scales and their distribution in the time domain. So we can tell the variation tendency of flow with different time scales. As shown in Fig. 4, precipitation in this area has two groups of significant periodic time scales, the first is 5 to 10 years and the second is 20 to 30 years.

The modulus of the wavelet coefficient is equivalent to the wavelet energy spectrum, depicting the oscillation energy of various periodic scales. We see that time scales of about 10- and 25-years are the most significant and strongest periodic scales (Fig. 5). The 25-year time scale occupies the whole time domain, and the 10-year time scale is most significant around 1980-2000.

To find out the primary period, wavelet variance was plotted in Fig. 7. The abscissa values of the two peaks indicate the most dominant periods; they are 10-years and 24-years for this station. That means the primary periods in this region are 10- and 24-years, and they control the changes of precipitation over the whole time domain.

The process line of the wavelet coefficient shows the wet-dry period under specific periodic scales. As shown in Fig. 8, for the 10-year time scale there are 7 wet-dry cycles, each of which is 
about 7-8 years. For the 24-year time scale, there are 3 cycles of about 18 years. We could project that the next peaks of the 10-year time scale may occur around 2013 and 2021, and that of 24-year time scale may be around 2013 and 2031.

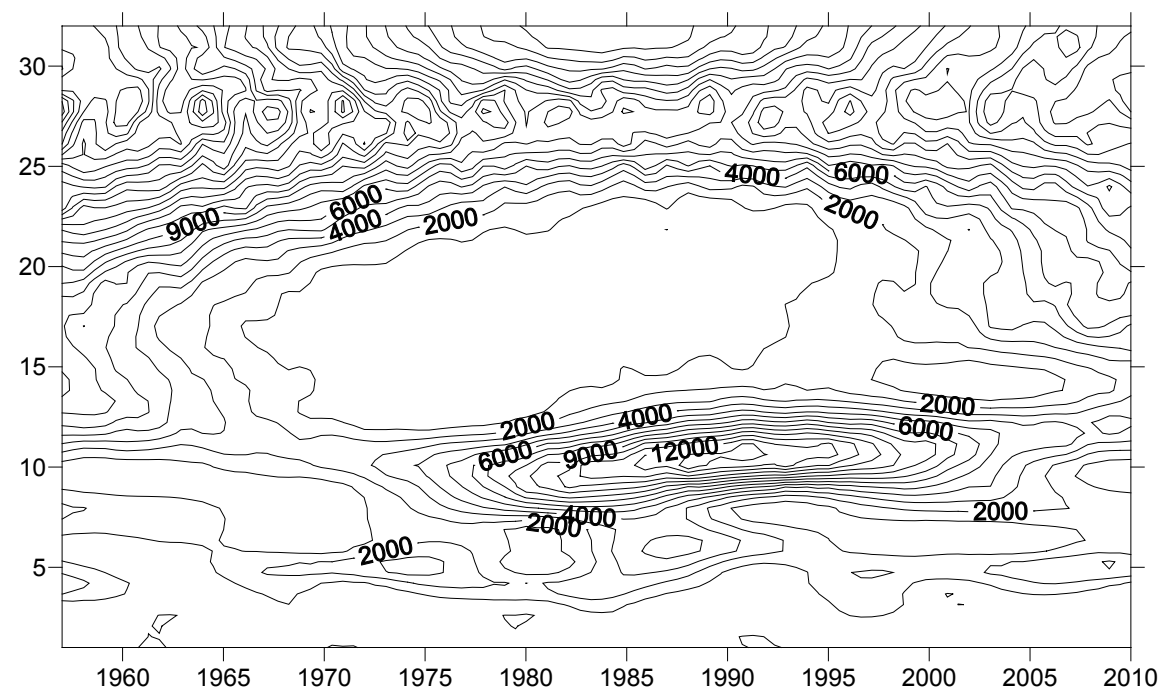

Fig. 5 Contour line of the wavelet coefficient modulus at the Argun Youqi station.

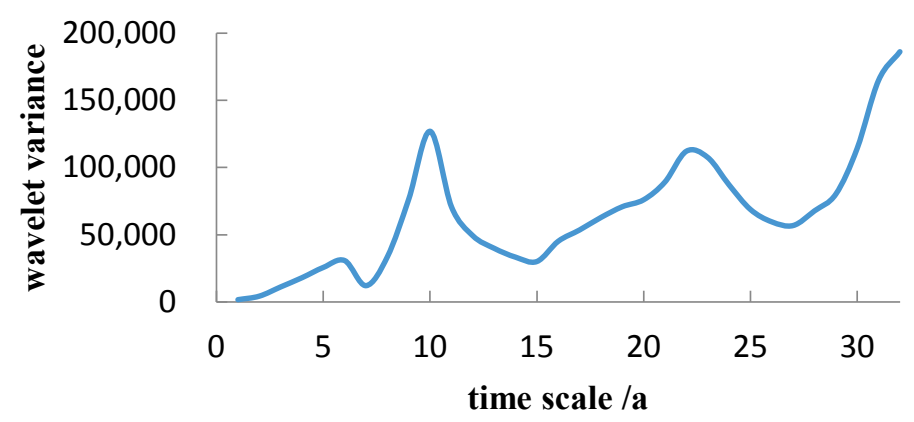

Fig. 6 Wavelet variance of precipitation at the Argun Youqi station.
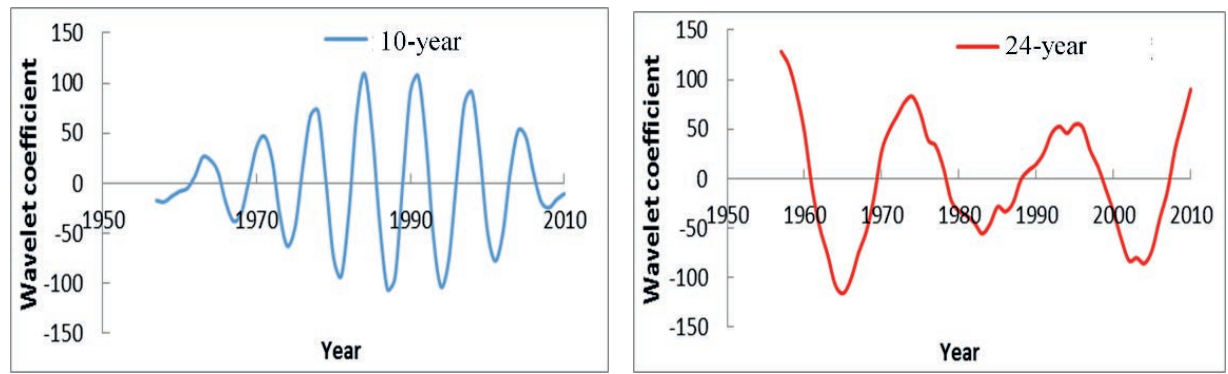

Fig. 7 Wavelet coefficient process of primary time scales (10-year and 24-year).

\section{TEMPORAL AND SPATIAL CHARACTERISTICS OF FLOWS}

Monthly flows as a percentage of yearly flow are calculated and plotted in Fig. 8(a). Most stations have a typical shape of "M", indicating that this region has two separate flood peaks in spring and summer. But Heishantou station, which is on a northern river, the Genhe River, has an overt single peak, which maybe due to low temperature in spring. August has the largest percentage 15-20\%, followed by July at about $15 \%$. January to March have the least, around $0.2-0.5 \%$.

The large loss is attributed to strong evaporation and small contribution from the lower stream tributaries in spring; the loss rate from the Bahou station to upper Argun River (Badaguan) could 
reach 40-60\%. While in summer, with the contribution from Genhe River, the flow could increase by as much as $200 \%$ (flow rate along the main stream of a dry year is plotted in Fig. 8 (b)).

Due to the significant linear loss, although Hailar River is the dominant water source for the upper stream of Argun River, the contribution of other tributaries and interval flow production are very important for the Argun River, especially in spring.
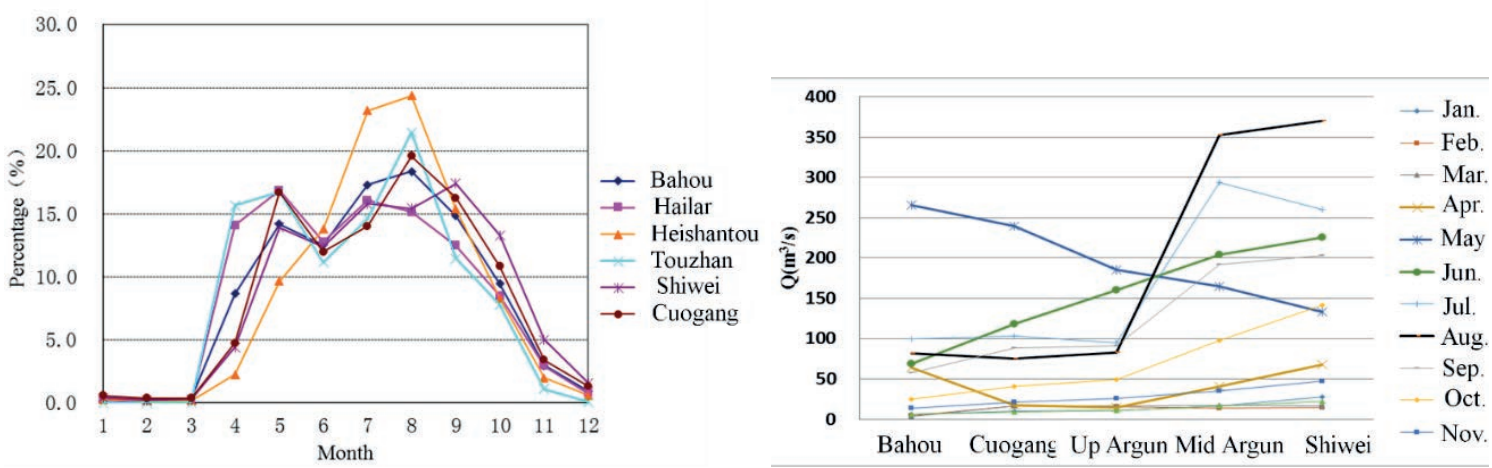

Fig. 8 (a) Temporal distribution of flow, and (b) spatial distribution of flow.

\section{CONCLUSIONS}

Based on multiple data and advanced technologies, this paper investigated the temporal characteristics and spatial distribution of water resources of the Argun River basin in the past, and projected to the future. The results illustrated that water resources of upstream regions trends to be declining, and the temporal distribution of the flow presents an "M" shape. The precipitation of this region has 10-year and 24-year scale primary periods. The period analysis is verified by the large flood which occurred in 2013; the next extremely wet year could be 2021.

With awareness of the evolutionary trend and specifications of water resources of the Argun River, we suggest proper water management measures be taken to optimize water use and that more attention given to water management in spring.

Acknowledgement This research is supported by the 2014 river management special fund of Ministry of Water Resources and National Natural Science Foundation of China (Grand No. 51409268).

\section{REFERENCES}

Gu, R.Y., et al. (2011) Characteristics of climate change in the Argun drainage basin during 1960-2008. Journal of Glaciology and Geocryology 33(6), 1310-1315.

Liu, M. C. (2005) Wavelet Analysis and Its Application. Tsinghua University Press, Beijing.

Mann, M.E., et al. (1998) Global scale temperature patterns and climate forcing over the past six centuries. Nature 392, 799-787.

Liu, X.M., et al. (2012) Dramatic decrease in streamflow from the headwater source in the central route of China's water diversion project: Climatic variation or human influence? Journal of Geophysical Research 117, D06113, doi:10.1029/2011JD016879.

Qiang, Z., et al. (2005) Precipitation, temperature and runoff analysis from 1950 to 2002 in the Yangtze basin, China, Hydrological Sciences Journal 50(1), 65-80.

Zhang, G.L., et al. (2011) Responses of vegetation changes to climatic variations in Hulun Buir grassland in past 30 years. Acta Geographica Sinica, 66(1), 47-58.

Zhao, H.Y. (2007) Impacts of climate change on forage potential climate productivity in typical grassland, Chinese Journal of Agrometeorology 28(3), 281-284. 